disappear. By 1914 "the distribution of commodities of all sorts in the United States was moving with a smoothness and precision unprecedented here or elsewhere in the world's history." But the war of 1914-18 completely disrupted the marketing system of the civilized world. New measures were employed by business and governments to meet new problems and needs, but the obstacles to adjustment were too severe and in many countries depression brought a regulated economy.

This book does not present much that is new in the way of facts-it follows the work of economic historians and could indeed be called an economic history of marketing. The work would have been stronger if it had included more of the business history of marketing, of the process or operation as contrasted with the institution or system. But such a history of marketing cannot be written until much further research has been done in the field. The author uses effectively the material at hand. In the light of that material he is justified in urging that in attacking our present problems we give attention to past experience. Failure to do so has meant repeating the mistakes of the past.

\title{
Proposed Economic History Association and Industrial History Society
}

There seems to be a strong interest at this time in the idea of national organization in the field of economic and industrial history. A group of economic historians and economists met during the annual session of the American Economic Association at Philadelphia, on December 29, 1939, to consider plans for organizing an American economic history society. A committee was elected to work out the final details for the proposed organization. The next day, at the meeting of the American Historical Association in Washington, a group of historians took similar steps towards the organization of an industrial history society. Final details remain to be worked out in both cases, and the feeling has been expressed by many that it would be well if the two groups could find a common ground for coöperation. Whatever may be the outcome, it is very heartening for those who work in economic and business history to see these moves towards greater activity and collaboration in the field. 